\title{
A Combined RMS-MEAN Value Approach for an Inverter Open-Circuit Fault Detection
}

\author{
Mohamed Amine Khelif ${ }^{\star *}$, Azeddine Bendiabdellah, Bilal Djamal Eddine Cherif ${ }^{1}$ \\ ${ }^{1}$ Diagnostic Group, LDEE Laboratory, Department of Electrical Engineering, Faculty of Electrical Engineering, \\ University of Science and Technology of Oran MB, BP 1505, El-Mnaouer Oran 31000, Algeria \\ * Corresponding author, e-mail: mohamed.khelif@univ-usto.dz
}

Received: 15 December 2018, Accepted: 20 February 2019, Published online: 04 April 2019

\begin{abstract}
Currently, with the power electronics evolution, a major research axis is oriented towards the diagnosis of converters supplying induction machines. Indeed, a converter such as the inverter is susceptible to have structural failures such as faulty leg and/or opencircuit IGBT faults. In this paper, the detection of the faulty leg and the localization of the open-circuit switch of an inverter are investigated. The fault detection technique used in this work is based essentially upon the monitoring of the root mean square (RMS) value and the calculation of the mean value of the three-phase currents. In the first part of the paper work, the faulty leg is detected by monitoring the RMS value of the three-phase currents and comparing them to the nominal value of the phase current. The second part, the open-circuit IGBT fault is localized simply by knowing the polarity of the calculated mean value current of the faulty phase. The work is first accomplished using simulation work and then the obtained simulation results are validated by experimental work conducted in our LDEE laboratory to illustrate the effectiveness, simplicity and rapidity of the proposed technique.
\end{abstract}

Keywords

detection, fault, IGBT, localization, open-circuit

\section{Introduction}

Nowadays, inverters are widely used in a variety of industrial applications such as variable speed drive applications, emergency power supplies, renewable energies, Solar photovoltaic and wind turbines systems, ... etc.. Their wide range of power and flexibility of use in terms of advances in power electronics have contributed to their success. This evolution has made it possible to reduce the cost and the size of the static converters, and to increase their reliability, as well as to exploit more efficient control techniques [1].

Research studies are now more interested in multi-level converters topologies. Currently, the Packed U Cell (PUC) converter is the most advanced topologies of all multi-level converters. Some researchers have mobilized their knowledge and skills to study this type of converter topology proposing improved design [2]. Their study has shown that this topology has the merit of reducing the number of switches as the number of levels. Hence, increasing reliability, reducing the cost of implementation, increase besides topology complexity compared to other existing topologies such as Neutral Point Clamping, Flying Capacitor, Cascaded $\mathrm{H}-\mathrm{Bridge}$ and Hybrid Cascaded H-Bridge. Authors in [3] address an implementation of transformer-less advanced multi-level topology in field of PV applications. They conclude that thanks to this topology, the shapes of the current and voltage are almost sinusoidal and a filter is not necessary. In another paper [4], searchers propose an interesting design and give an analysis study of hybrid photovoltaic-fuel cell power generation system for a PUC Topology. All the studies cited previously confirm the merits of this competitive multi-level PUC topology and highlight the benefits of using this advanced PUC design.

Space Vector Pulse Width Modulation (SVPWM) is a universal technique that is one of the most suitable for induction motor control and the most widely used in industry [5]. Despite the fact that electric drives are considered robust compared to other types of drives, these assemblies are exposed to the risk of failure. A feedback from a conducted industry study on medium-power drives confirms that most of the faults of a converter-motor system occur in the converter with its control [6]. Fig. 1 depicts a percentage of faults distribution in static converters. By statistics, $38 \%$ of the faults are linked to the converters and $31 \%$ of the 


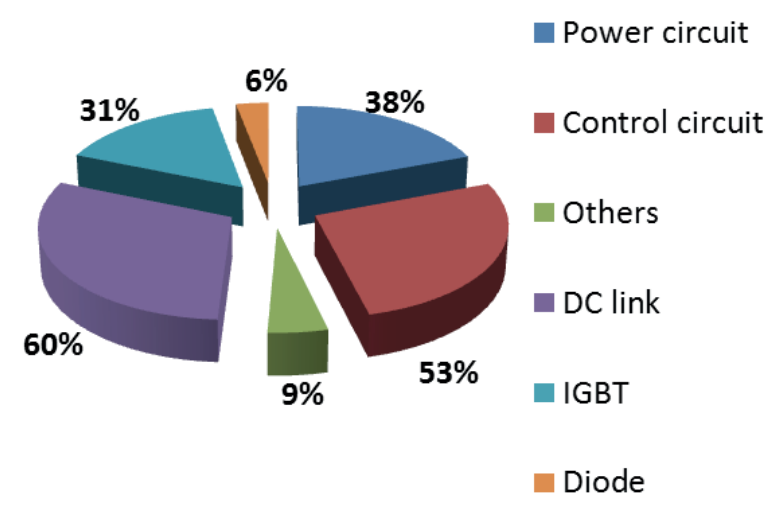

Fig. 1 Percentage faults distribution in a static inverter

faults occur at the level of IGBT switches which are essential elements of the commutation in static converters [7, 8].

It is to be noted that the fault detection of these switching elements is almost difficult because the voltage and current vary rapidly compared to the normal operation. This failure type causes severe constraints that can lead to secondary faults in the inverter, the motor or the load, leading to a degraded performance system and may damage it [6]. It is therefore obvious that the investment in the field of detection of faults seems an inevitable solution. Several researchers have carried out their investigation in relation to the field of faults detection and localization in static converters and more particularly those related to three-phase power inverters $[9,10]$.

The IGBT switch failures in static converters can be divided into two categories: short-circuit faults and open-circuit faults [11]. The short-circuit IGBT faults are caused by gate circuit degradation, impact ionization, bond wire rupture, and over- current [12]. The system can shut down in case of this type of failure, because circuits protection (circuit breakers and fuses) are blocking its sources [13]. The open-switch faults can be usually caused either by device driver failures, the connections rupture leaded by over-heating or the lift of bonding wire resulting from thermic cycling [13]. Contrary to short-circuit faults that cause system shutdown, open switch IGBT faults do not, but induce to the degradation of its performance. Most of the diagnosis works are therefore devoted to the inverter open-circuit fault IGBT switches [9, 14, 15].

Most of published papers on open-circuit fault detection are based on the Park's current vectors approach. The detection is done by monitoring the current's trajectory in the d-q frame. Indeed, the last draws a complete circle in the case of a healthy state, and becomes a semicircle when an open-circuit IGBT fault occurs, and the circle orientation allows to localize the faulty IGBT [14]. In order to localize the faulty IGBT switch, another paper work used the mean value of the phase currents in Park's frame to extract the open-circuit fault angle of each IGBT switch [15]. This method presents unfortunately an inconvenient as it depends on the load. To overcome the problem, the normalized DC current method was suggested by some authors; which is mainly based on the calculation of the dc component of the current and the first order harmonic coefficients of the three-phase currents [8]. The Park's current vectors approach has been improved by employing the polar coordinates to calculate the exact angles of each IGBT switch [16]. A review of some detection techniques mentioned above are discussed and compared in $[8,10]$. Spectral analysis techniques are preferred by other researchers. In these techniques, the current spectrum is analyzed to detect the harmonics characterizing the faulty open-circuit IGBT switch. A fast Fourier transform is used for the spectrum analysis; a relatively high computing power is required [17]. Another paper presents the analysis of an inverter switching faults using the Short Time Fourier Transform (STFT) [18]. To overcome false diagnosis alarms and increasing the robustness under wide range load condition, fuzzy logic or neural network based approaches can be applied [19, 20]. Some authors use fuzzy logic technique associated with the Park vectors for the diagnosis of faults in an inverter fed induction motor [20]. Another work presents a discrete wavelet transform (DWT) diagnostic technique associated with neural network (NN) algorithm [19]. It is to be noted that the time detection of the open-circuit IGBT fault is over a fundamental current period [8].

The monitoring of the RMS value of the electrical quantities of a system is a standard approach in almost all industrial installations. Based on this fact, some researchers [21] proposed a special RMS voltage-based fault diagnosis method for open Switch Fault in Wind System permanent magnet synchronous generator (PMSG) drives. The detection process is done without threshold setting. Others researchers [22] had the idea to build his approach of IGBT open-circuit fault detection on the monitoring and comparison of the instantaneous RMS value of the current of a DC-DC converter at the rated normal RMS. The significant change in the RMS value relative to the normal RMS is considered as an indication of the fault detection and localization. This diagnostic process based on the RMS value, is both simple and effective. 
The aim of this paper is to propose a simple and efficient technique based on the monitoring of the RMS value combined with the calculation of the mean value of the inverter three-phase currents in order to detect and to localize an open-circuit IGBT switch fault of a two-level three-phase inverter.

\section{Fault analysis of an IGBT open-circuit and its impact on the inverter phase currents shape}

Fig. 2 shows a structure of a two-level three-phase inverter fed induction motor. This inverter is controlled by the PWM vector control strategy.

\subsection{Healthy state case}

Fig. 3 shows the three-phase currents for the case of a healthy inverter. It can be observed that the phase current takes the form of an almost perfect sinusoid. It is to be noted that, in all the following three-phase currents waveforms; the current $i_{a}$ is assigned in blue color, the current $i_{b}$ is assigned in green color and the current $i_{c}$ is assigned in red color.

Fig. 4 depicts respectively the RMS value and the mean value of the three-phase currents for the healthy inverter

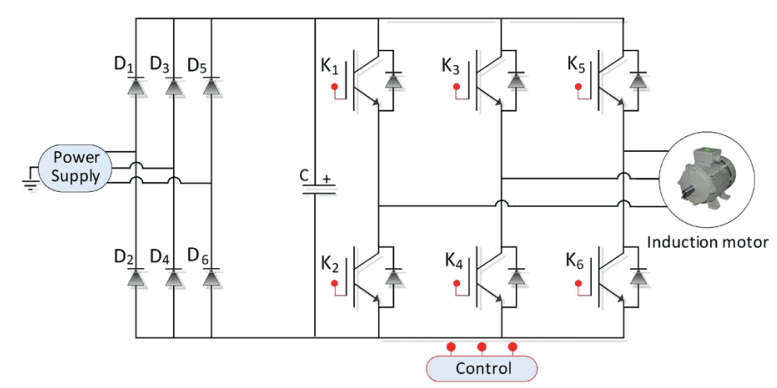

Fig. 2 Three-phase two-level inverter structure fed induction motor

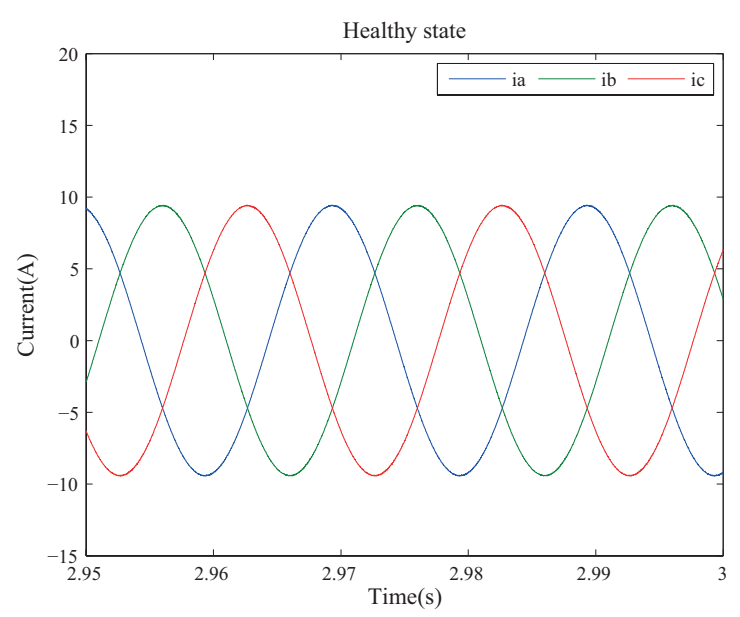

Fig. 3 Three-phase currents waveforms $i_{a}, i_{b}$ and $i_{c}$ for healthy inverter case
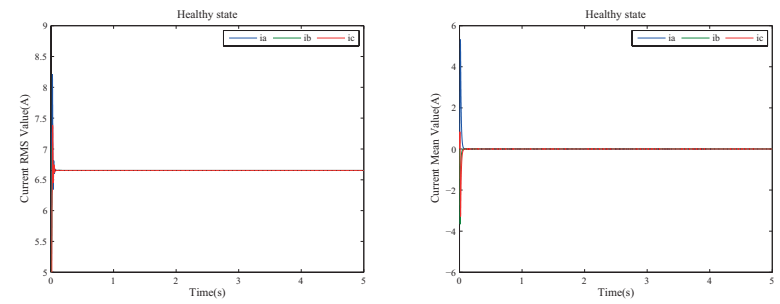

Fig. 4 Three-phase currents RMS-value and three-phase currents mean-value for healthy inverter case

case. It is seen that the RMS currents are at the rated value, and the mean-value current are zero for the threephase currents $\left(i_{a}, i_{b}\right.$, and $\left.i_{c}\right)$.

\subsection{Faulty case state}

Fig. 5 shows the waveforms of the inverter three-phase currents for the faulty inverter case. As an example, a fault that appears in phase $A$ is considered occurring in a faulty leg- $A$ of the three-phase voltage inverter. This implies that this may be an open-circuit fault of the IGBT switch $K_{1}$ or an open-circuit fault of its complement the IGBT switch $K_{2}$.

As shown in Fig. 5, it can be observed that the threephase currents change in shape at the instant of the IGBT $K_{1}$ open-circuit fault application. The current of phase $A$ loses its positive alternation and its amplitude increases. As for the phase $B$, its current keeps its quasi-sinusoidal shape but its amplitude also increases. For the phase $C$, the current also keeps its quasi-sinusoidal form but its amplitude decreases. It can also be seen that the two phase currents $B$ and $C$ are shifted upwards.

In the case of an open-circuit fault of the IGBT $K_{2}$ (complement of $K_{1}$ ), it can be observed from Fig. 5 that the current of the phase $A$ this time loses its negative alternation and its amplitude also increases. As for the phase $B$, the current maintains its quasi-sinusoidal shape but its amplitude also increases. For the phase $C$, the current also keeps its quasi-sinusoidal form but its amplitude decreases. In this case, the two phase currents $B$ and $C$ are seen to be shifted downwards.
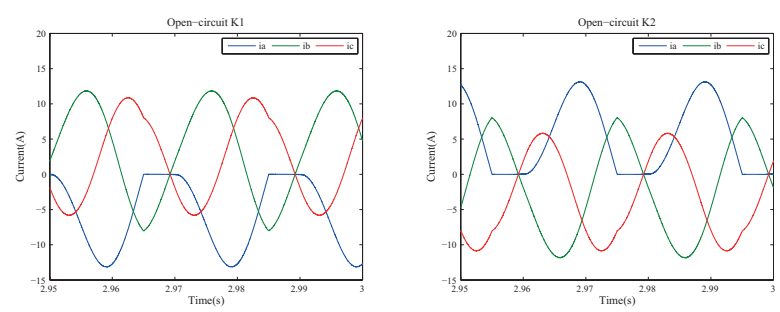

Fig. 5 Three-phase currents waveforms $i_{a}, i_{b}$ and $i_{c}$ for IGBT open-circuit at $K_{1}$ and $K_{2}$ 


\section{Description of the detection and localization technique of a faulty inverter}

Inspired by the idea found in the approach of reference [19], this paper work consists of developing an IGBT open-circuit fault detection and localization technique based on the monitoring of the RMS and the calculation of the mean value of the currents of a two-stage three-phase voltage inverter. The RMS value is the most commonly used term in the educational and industrial communities. The monitoring of the RMS value of the nominal currents (or nominal voltages) has become a standard. The majority of the industrial electrical systems have a display panel that allows the reading of their instantaneous values.

The values that need to be monitored and calculated are by definition the RMS and the mean values over one period $T$ of a current signal $i(t)$ [23].

$$
\begin{aligned}
& i_{\text {RMS }}=\sqrt{\frac{1}{T} \int_{0}^{T} i^{2}(t) d t} \\
& i_{\text {Mean }}=\frac{1}{T} \int_{0}^{T} i(t) d t .
\end{aligned}
$$

The discrete equations are given below as follows:

$$
\begin{aligned}
& i_{R M S}=\sqrt{\frac{1}{N} \sum_{n=0}^{N-1} i^{2}(n)} \\
& i_{\text {Mean }}=\frac{1}{N} \sum_{n=0}^{N-1} i(n) .
\end{aligned}
$$

Where, the values $i(n)$ and $i^{2}(n)$ are the samples of the periodic signal and $N$ is the number of samples during one period $T$. The $N$ samples are equally spaced along one complete signal period.

The following flowchart in Fig. 6 explains first the procedure of detecting the faulty arm and later the IGBT switch fault localization.

\subsection{Inverter faulty leg detection}

To begin, three current sensors are placed to monitor the evolution of the RMS current in each of the three phases. In the healthy state, the effective value of the current in the three phases $A, B$, and $C$ is equal to the nominal RMS value of the phase current $i_{r R M S}$. When the fault occurs (let say applied at time $t=1.5 \mathrm{~s}$ ), the RMS values of these three-phase currents change with the amplitude change of the three-phase currents. The detection of the faulty arm is done by comparing the new effective value of the current of each phase with the nominal RMS value of the phase current.

Fig. 7 depicts respectively the evolution of the RMS and the mean values of the three-phase currents of the inverter under the faulty legs $A, B$ and $C$.

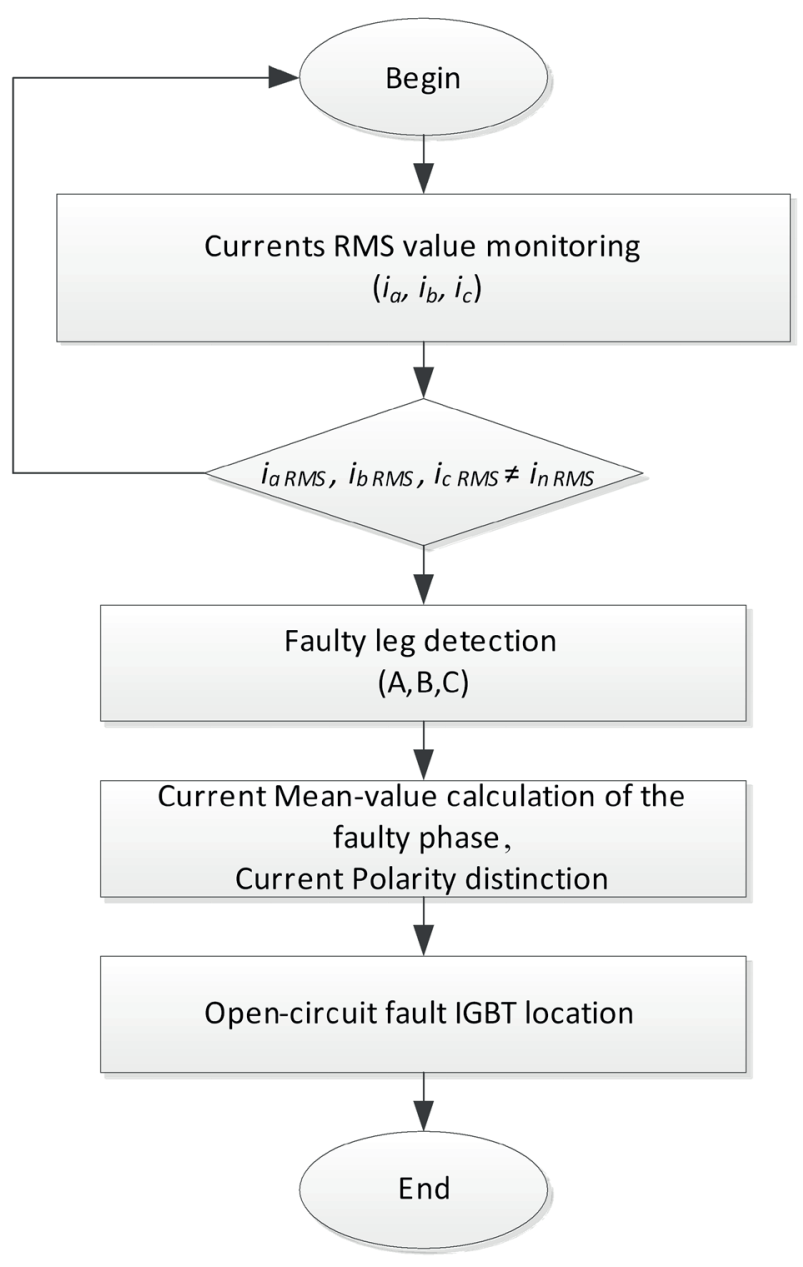

Fig. 6 Flowchart of the fault detection and localization technique

As shown in Fig. 7, when a fault occurs in the leg- $A$ of the inverter, the monitoring of the RMS value of the currents shows an increase in the phases $A$ and phase $B$ and a decrease in the phase $C$. When a fault reaches the leg- $B$, the monitoring of the RMS value of the currents shows an increase in the phases $B$ and phase $C$ and a decreases in
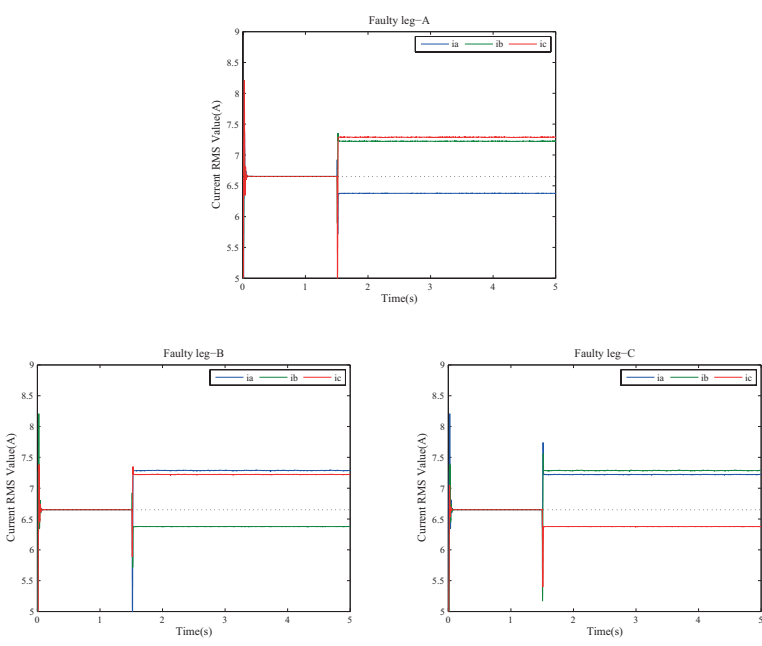

Fig. 7 Evolution of the RMS value of the three-phase currents 
the phase $A$. And finally, when a fault occurs in the leg- $C$, the monitoring of the RMS value of the currents shows an increase in the phases $C$ and phase $A$ and a decrease in the phase $B$. It can be concluded from these findings that for each case of an inverter leg opening fault, the RMS value of the current decreases in one phase and increases in the other two phases.

\subsection{Inverter faulty IGBT switch localization}

The IGBT fault localization is achieved by the calculation of the mean value of the phase current of the faulty leg. In the healthy state $i_{a \text { Mean }}, i_{b \text { Mean }}, i_{c \text { Mean }}$ are zero. By cons, in the event of a fault these mean values of phase currents take values other than zero. The positive or negative sign of the mean value of the current of the phase connected to the faulty leg allows us to localize the faulty IGBT.

Fig. 8 shows the evolution of the mean value of the three-phase currents of the inverter in the presence of an open-circuit fault of each one of the six IGBT switches constituting the three legs of the three-phase voltage inverter.

As shown in Fig. 8, when the mean value of the current of the faulty phase is negative, this implies that the faulty IGBT switch is that at the top. By cons, if the mean value of the current of the faulty phase is positive, this implies that the faulty IGBT switch is the one at the bottom. Let us
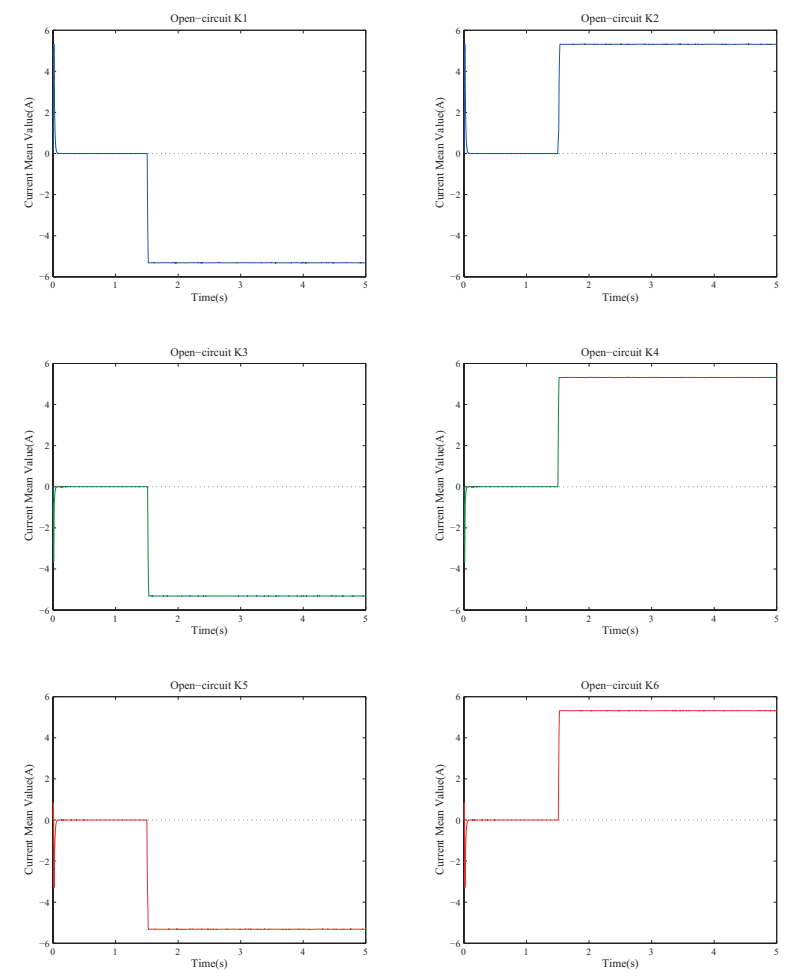

Fig. 8 Currents RMS-value and currents Mean-value for the case of IGBT fault $K_{1}, K_{2}, K_{3}, K_{4}, K_{5}$ and $K_{6}$ now consider as an example the leg-A which consists of two IGBT switches $K_{1}$ and $K_{2}$. When a fault occurs at the IGBT $K_{1}$ level, the mean value of the current of the phase A takes a negative value (the polarity is negative). By cons, when a fault occurs at the IGBT $K_{2}$ level (the complementary of $K_{1}$ ), the mean value of the current of the phase $A$ takes a positive value (the polarity is positive).

Table 1 summarizes the three possibilities defining the fault opening of the three legs $A, B$ and $C$ respectively and hence also the fault possibilities of the IGBT switches $K_{1}$, $K_{2}, K_{3}, K_{4}, K_{5}$, and $K_{6}$ for the case of a three-phase inverter.

With

- $i_{r \text { RMS }}$ : Nominal RMS value of the phase current (Rated RMS current value).

- $i_{a \text { RMS }}, i_{b R M S}, i_{c R M S}$ : RMS values of the currents of phase $A$, phase $B$ and phase $C$ respectively.

- $i_{a \text { Mean }}, i_{b \text { Mean }}, i_{c \text { Mean }}$ : Mean values of the currents of phase $A$, phase $B$ and phase $C$ respectively.

The choice to use a combination of different types of values (RMS value and mean value) is to combine efficiency, speed and robustness against false alarms. Monitoring the RMS value of the current makes it possible to quickly detect the faulty leg (faulty phase). The polarity of the mean value of the faulty phase current makes it possible to localize the faulty IGBT switch.

\section{Experimental results}

At this stage of the paper, it is to note that all the simulation results obtained and illustrated by the various graphs above are validated using the experimental work. The experimental results which are presented in the following part of this paper work are conducted using the test-rig built by the Group Diagnostic in the LDEE laboratory at the university USTO-MB shown in the photo of Fig. 9 the acquisition time will be taken as $T_{a c q}=5 \mathrm{~s}$ and the sampling frequency $\mathrm{Fe}=1500 \mathrm{~Hz}$. The inverter is a fabricated "SEMIKRON SEMITEACH-IGBT" model controlled by a dSPACE 1104 board. "FLUKE i30s"

Table 1 Proposed detection and localization method

\begin{tabular}{lccl}
\hline Leg & conditions & \multicolumn{1}{c}{ IGBT switches } \\
\hline Faulty & $i_{a R M S} \leq i_{r R M S^{\prime}} i_{b R M S}>i_{r R M S}$ and & Open-circuit $K_{1}$ & $i_{a M e a n}<0$ \\
Leg-A & $i_{c R M S}>i_{r R M S}$ & Open-circuit $K_{2}$ & $i_{a M e a n}>0$ \\
Faulty & $i_{a R M S}>i_{r R M S^{\prime}} i_{b R M S} \leq i_{r R M S}$ & Open-circuit $K_{3}$ & $i_{b M e a n}<0$ \\
Leg-B & and $i_{c R M S}>i_{r R M S}$ & Open-circuit $K_{4} \quad i_{b M e a n}>0$ \\
Faulty & $i_{a R M S}>i_{r R M S^{\prime}} i_{b R M S}>i_{r R M S}$ & Open-circuit $K_{5}$ & $i_{c M e a n}<0$ \\
Leg-C & and $i_{c R M S} \leq i_{r R M S}$ & Open-circuit $K_{6}$ & $i_{c M e a n}>0$ \\
\hline
\end{tabular}




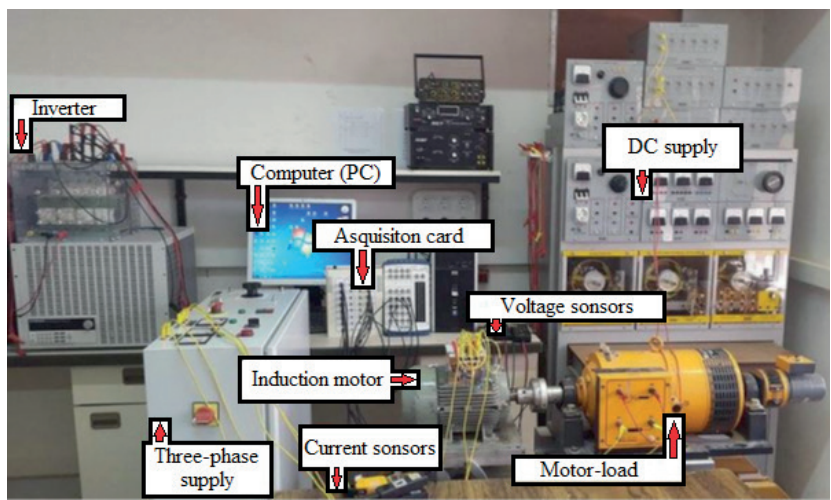

Fig. 9 Photo of the experimental test-rig

current clamp sensors and "Tektronix P5200" voltage sensors are used.

Fig. 10 depicts the experimental results of the three-phase waveforms currents $\left(i_{a}, i_{b}\right.$ and $\left.i_{c}\right)$ for the healthy inverter case.

Fig. 11 shows the experimental results of the RMS value and the mean value for each of the three phases in the healthy inverter case.

Fig. 12 shows the waveform of the three-phase currents in case of presence of an open-circuit fault at the IGBT switch $K_{1}$ and its complementary the IGBT switch $K_{2}$.

Fig. 13 shows the experimental results of the evolution of the RMS value for each of the three phases when a fault occurs in the three legs $A, B$ and $C$ respectively when an IGBT $K_{1}$ fault and its IGBT $K_{2}$ complementary occur.

Fig. 14 shows the experimental results of the evolution of the mean value for each one of the three phases when a fault occurs in the IGBT switches $K_{1}, K_{2}, K_{3}, K_{4}, K_{5}$ and $K_{6}$.

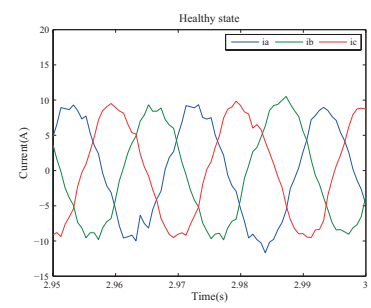

Fig. 10 Three-phase currents waveforms $i_{a}, i_{b}$ and $i_{c}$ for healthy case (experimental results)
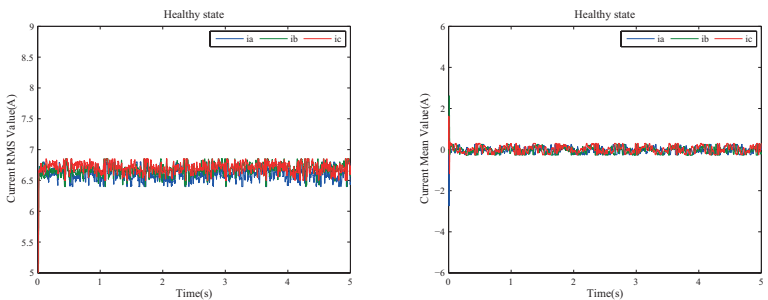

Fig. 11 Three-phase currents RMS-value and three-phase currents mean-value for healthy inverter case (experimental results)
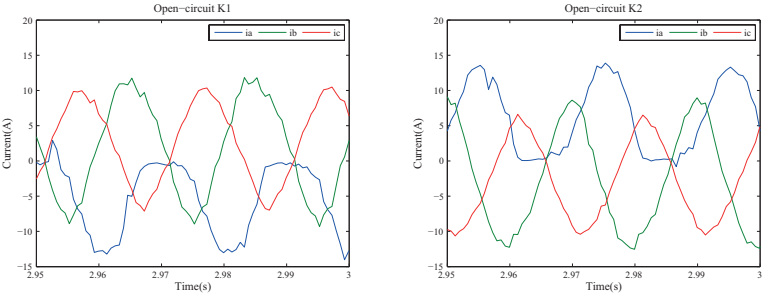

Fig. 12 Three-phase Currents waveforms $i_{a}, i_{b}$ and $i_{c}$ for IGBT open-circuit at $K_{1}$ and $K_{2}$ (experimental results)
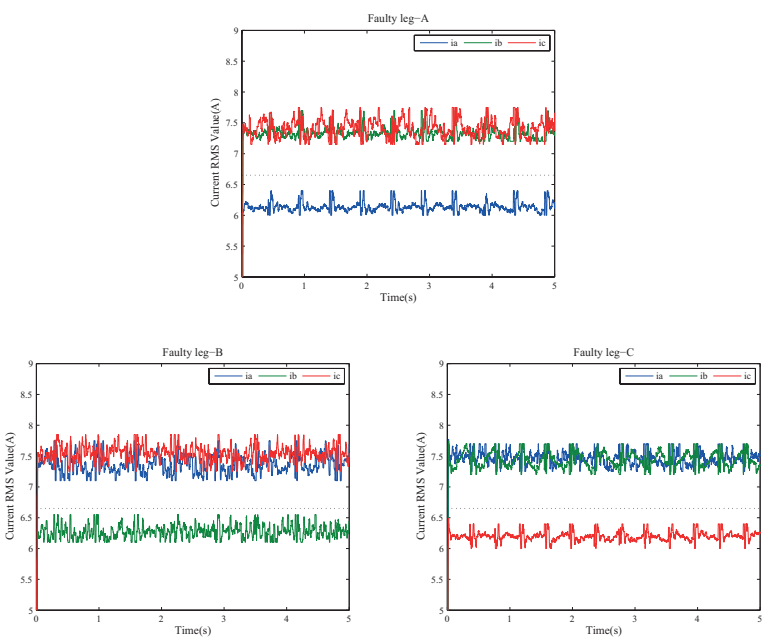

Fig. 13 Evolution of the RMS value of the three-phase currents (experimental results)

\section{Conclusions}

In this paper, a method for detecting an inverter open leg fault and localizing an IGBT switch open-circuit fault of an IGBT is presented. Several simulation results have been given to illustrate the merits of the method and its effectiveness. An experimental work is also conducted to validate the results obtained through the simulation. This method has the advantage of being simple, effective and reliable while being based on the monitoring of the RMS value of the three-phase currents and the calculation of the mean value of the threephase currents of the faulty phase.

The monitoring of the RMS current enables us not only to detect the faulty leg but also to know the severity of the fault in each phase. If the current has increased that means that the severity has become important. This method makes it possible also to more quickly detect the faulty leg which is favorable for the use of redundant legs and can be implemented at a low cost. The calculation of the mean value of the current of the phase connected to the faulty leg is sufficient for the localization of the faulty upper or lower IGBT switch and therefore the proposed detection method allows a fast detection time for IGBT switch localization. 

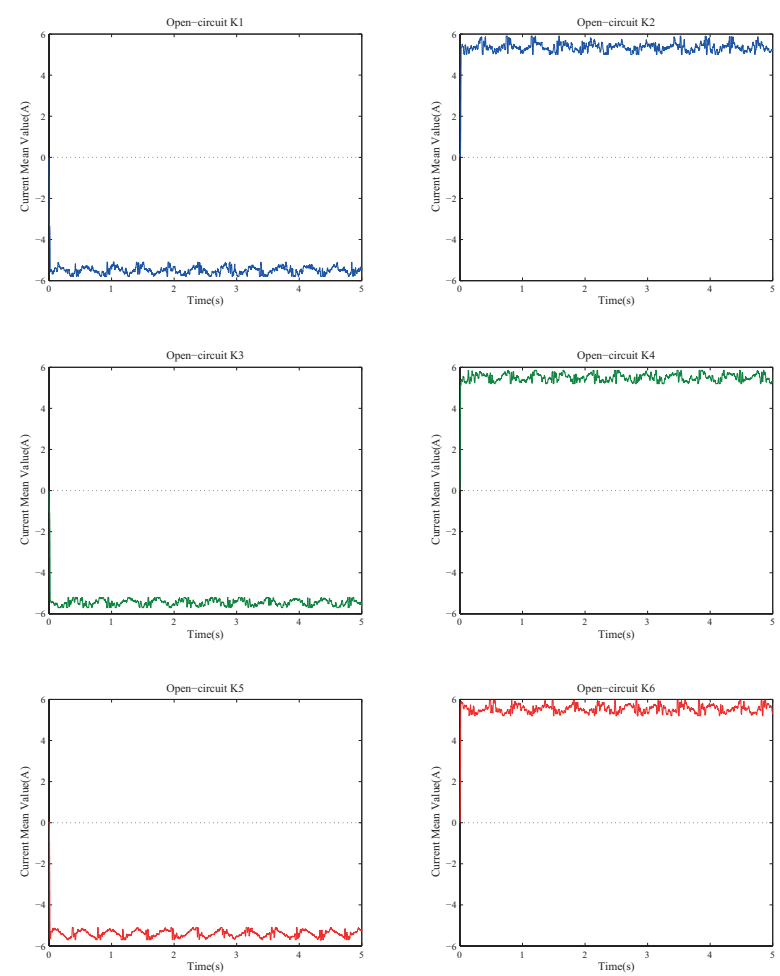

Fig. 14 Evolution of the mean value of the three-phase currents for the case of IGBT switches faults $K_{1}, K_{2}, K_{3}, K_{4}, K_{5}$ and $K_{6}$ (experimental results)

The normalization of the currents requires a spectral analysis in order to calculate the two essential normalized coefficients for this procedure. By cons, with the proposed method in this paper, this step is completely eliminated since the proposed method relies essentially on the monitoring of the RMS value of the currents at first for the detection of the faulty leg and on a simple computation of the mean value of the currents thereafter for the open-circuit fault localization of an IGBT switch by simply distinguishing the polarity of the mean value of the current of the faulty phase.

\section{Annexes}

\section{Nomenclature}

$\mathrm{a}, \mathrm{b}, \mathrm{c} \quad$ Indexes corresponding to three phases

$(a),(b),(c)$

C Capacitor

$\mathrm{Fe} \quad$ Sampling frequency

$\begin{array}{ll}i a & \text { Stator current phase } A \\ i_{a \text { Mean }} & \text { Mean value of the stator current of the phase } A \\ i_{a R M S} & \begin{array}{l}\text { Root Mean Square value of the stator current } \\ \text { of the phase } A\end{array} \\ i b & \text { Stator current phase } B \\ i_{b \text { Mean }} & \text { Mean value of the stator current of the phase } B \\ i_{b R M S} & \text { Root Mean Square value of the stator current } \\ & \text { of the phase } B \\ i c & \text { Stator current phase } C \\ i_{c \text { Mean }} & \text { Mean value of the stator current of the phase } C \\ i_{c R M S} & \text { Root Mean Square value of stator current } \\ I_{G B T} & \text { phase } C \\ i_{r R M S} & \text { Insulated Gate Bipolar Transistor } \\ K_{1 \ldots 6} & \text { Rated RMS current value } \\ L & \text { Inverter switches } \\ P M S G & \text { Inductance } \\ P W M & \text { Permanent magnet synchronous generator } \\ R & \text { Pulse Width Modulation } \\ R M S & \text { Resistance } \\ S V M & \text { Root Mean Square } \\ T & \text { Space Vector Modulation } \\ T_{a c q} & \text { Signal period } \\ U P S & \text { Time acquisition } \\ V d c & \text { Uninterruptible Power Supplies } \\ & \text { DC voltage }\end{array}$

Induction motor parameters

Power supply $380 \mathrm{~V}$

Coupling $\Delta$

Rated power $3 \mathrm{~kW}$

Nominal current $7 \mathrm{~A}$

Rated speed $1410 \mathrm{tr} / \mathrm{min}$

Stator resistance

$6 \Omega$

Rotor resistance

Stator cyclic inductance

$0.5668 \Omega$

Rotor cyclic inductance

$0.5142 \Omega$

Mutual inductance

$0.5142 \Omega$

Poles pairs number

2

Moment of inertia

0.058 kg. $\mathrm{m}^{2}$

Load torque

20 N.m

Coefficient of viscous friction 


\section{References}

[1] Dokić, B. L., Blanuš, B. "Power electronics converters and regulators", 3th ed., Springer, Cham, Switzerland, 2015.

https://doi.org/10.1007/978-3-319-09402-1

[2] Rajanand Patnaik, N., Ravindranath Tagore, Y. "Design and Evaluation of PUC (Packed U Cell) Topology at Different Levels \& Loads in Terms of THD", European Journal of Advances in Engineering and Technology, 3(9), pp. 33-43, 2016. [online] Available at: http://www.ejaet.com/PDF/3-9/EJAET-3-9-33-43. pdf [Accessed: 28 January 2019]

[3] Rajanand Patnaik, N., Tagore, Y., Chaitanya, S. "Advanced seven level transformer-less multilevel inverter topology for PV application", In: Third International Conference on Advances in Electrical, Electronics, Information, Communication and BioInformatics, Chennai, India, 2017, pp. 111-116. https://doi.org/10.1109/aeeicb.2017.7972393

[4] Narasipuram, R. P. "Optimal design and analysis of hybrid photovoltaic-fuel cell power generation system for an advanced converter technologies", International Journal of Mathematical Modelling and Numerical Optimisation, 8(3), pp. 245-276, 2018. https://doi.org/10.1504/IJMMNO.2018.088990

[5] Melkebeek, J. A. "Basics of Controlled Electrical Drives, Electrical Machines and Drives", Power Systems, Springer, Cham, Switzerland, 2018.

https://doi.org/10.1007/978-3-319-72730-1 17

[6] Riera-Guasp, M., Antonino-Daviu, J. A., Capolino, G. A. "Advances in electrical machine, power electronic and drive condition monitoring and fault detection: State of the art", IEEE Transactions on Industrial Electronics, 62(3), pp. 1746-1759, 2015. https://doi.org/10.1109/TIE.2014.2375853

[7] Yang, S., Bryant, A., Mawby, P., Xiang, D., Ran, L., Tavner P. "An Industry-Based Survey of Reliability in Power Electronic Converters", IEEE Transactions on Industry Applications, 47(3), pp. 1441-1451, 2011.

https://doi.org/10.1109/TIA.2011.2124436

[8] Lu, B., Sharma, S. K. "A Literature Review of IGBT Fault Diagnostic and Protection Methods for Power Inverters", IEEE Transactions on Industry Applications, 45(5), pp. 1770-1777, 2009. https://doi.org/10.1109/TIA.2009.2027535

[9] Cherif, B. D. E., Bendiabdellah, A., Bendjebbar, M., Telli, A. "A comparative study between methods of detection and localisation of open-circuit faults in a three phase voltage inverter fed induction motor", International Journal of Modelling, Identification and Control, 29(4), pp. 327-340, 2018.

https://doi.org/10.1504/IJMIC.2018.10013129

[10] Cherif, B. D. E., Bendiabdellah, A., Bendjebbar, M., Laribi, S. "A Comparative Study on Some Fault Diagnosis Techniques in Three-Phase Inverter Fed Induction Motors", In: Fault Detection and Diagnosis, IntechOpen, London, United Kingdom 2018, pp. 77-98. https://doi.org/10.5772/intechopen.79960

[11] Wu, R., Blaabjerg, F., Wang, H., Liserre, M., Iannuzzo, F. "Catastrophic failure and fault-tolerant design of IGBT power electronic converters - an overview", In: IECON 2013 - 39 Annual Conference of the IEEE Industrial Electronics Society, Vienna, Austria, 2013, pp. 507-513. https://doi.org/10.1109/IECON.2013.6699187
[12] Oh, H., Han, B., McCluskey, P., Han, C., Youn, B. D. "Physicsof-Failure, Condition Monitoring, and Prognostics of Insulated Gate Bipolar Transistor Modules: A Review", IEEE Transactions on Power Electronics, 30(5), pp. 2413-2426, 2015.

https://doi.org/10.1109/TPEL.2014.2346485

[13] Gopi Reddy, L., Tolbert, L., Ozpineci, B. "Power Cycle Testing of Power Switches: A Literature Survey", IEEE Transactions on Power Electronics, 30(5), pp. 2465-2473, 2015. https://doi.org/10.1109/TPEL.2014.2359015

[14] Raj, N., Mathew, J., Jagadanand, G., George, S. "Open-transistor Fault Detection and Diagnosis Based on Current Trajectory in a Two-level Voltage Source Inverter", Procedia Technology, Global Colloquium in Recent Advancement and Effectual Researches in Engineering, Science and Technology, 25, pp. 669-675, 2016. https://doi.org/10.1016/j.protcy.2016.08.159

[15] Cherif, B. D. E., Bendiabdellah, A., Khelif, M. A. "Detection of Open-Circuit Fault in a Three-Phase Voltage Inverter Fed Induction Motor", International Review of Automatic Control, 9(6), pp. 374-382, 2016.

https://doi.org/10.15866/ireaco.v9i6.10268

[16] Cherif, B. D. E., Bendiabdellah, A., Khelif, M. A., Bendjabbar, M. Benouzza, N. "The enhancement of park current vectors technique for inverter fault detection", In: Proceedings of the $6^{\text {th }}$ International Conference on Systems and Control, Batna, Algeria, 2017, pp. 377-382.

https://doi.org/10.1109/ICoSC.2017.7958646

[17] Abdullah, A. R., Ahmad, N. S., Shair, E. F., Jidin, A. "Open switch faults analysis in voltage source inverter using spectrogram", In: IEEE $7^{\text {th }}$ International Power Engineering and Optimization Conference, Langkawi, Malaysia, 2013, pp. 438-443. https://doi.org/10.1109/PEOCO.2013.6564588

[18] Ahmad, N., Abdullah, A., Bahari, N., Hassan, M. "Switches Faults Analysis of Voltage Source Inverter (VSI) using Short Time Fourier Transform (STFT)", International Review on Modelling and Simulations, 7(3), pp. 409-415, 2014. [online] Available at: https://www.researchgate.net/publication/273634913_Switched Faults_Analysis_of_Voltage_Source_Inverter_VSI_using Short_Time_Fourier_Transform_STFT [Accessed: 06 May 2018]

[19] Cherif, B. D. E., Bendiabdellah, A. "Detection of two-level inverter open circuit fault using a combined DWT-NN approach", Journal of Control Science and Engineering, 2018, Article ID 1976836, 2018. https://doi.org/10.1155/2018/1976836

[20] Chen, C. C., Lin, Y. H., Ke, B. R., Hsue, C. W., Hsieh, H. C. "Fault leg detection for open-circuit faults in PWM voltage-source inverters of renewable energy via the fuzzy logic diagnostic method", Journal of Technology, 32(4), pp. 299-308, 2017. [online] Available at: http://jot.ntust.edu.tw/index.php/jot/article/ viewFile/566/142 [Accessed: 22 October 2018]

[21] Yanghong, T., Haixia, Z., Ye, Z. "A Simple-to-Implement Fault Diagnosis Method for Open Switch Fault in Wind System PMSG Drives without Threshold Setting", Energies, 11(10), pp. 1-18, 2018. https://doi.org/10.3390/en11102571 
[22] Chavan, S. B., Chavan, M. S. "A model based approach for fault diagnosis in converter of photovoltaic system", In: IEEE global conference on wireless computing and networking, Lonavala, India 2014, pp. 112-115.

https://doi.org/10.1109/GCWCN.2014.7030859

[23] Mog, G. E., Ribeiro, E. P. "Mean and RMS calculations for sampled periodic signals with non-integer number of samples per period applied to AC energy systems", In: Congresso Ibero-LatinoAmericano de M'etodos Computacionais em Engenharia-XXV Iberian Latin American Congress on Computational Methods in Engineering, Recife, Pernambuco, Brazil, 2004. [online] Available at: http://www.eletrica.ufpr.br/edu/artigos/CIL22-012_final_gerson.pdf [Accessed: 04 November 2018] 